\title{
Anti-inflammatory mechanism of Isodon japonicas (Burm) Hara on lipopolysaccharide-induced neuroinflammation
}

\author{
Hyun Kang \\ Department of Medical Laboratory Science, College of Health Science, Dankook University, Cheonan-si, Chungnam, 31116 , \\ Republic of Korea \\ *For correspondence: Email: hyunkang2@gmail.com, hkang@dankook.ac.kr; Tel: 82-41-550-3015; Fax: 82-41-559-7934
}

\begin{abstract}
Purpose: To investigate the anti-neuroinflammatory effects of Isodon japonicus (Burm.) Hara extract (IJE) on BV2 microglial cells. .

Methods: Cell viability was evaluated by MTT method. BV2 microglial cells were stimulated with lipopolyscarride (LPS, $1 \mathrm{\mu g} / \mathrm{ml}$ ) and the effect of IJE on nitric oxide (NO) levels were measured using Griess assay. Immunoblot analysis was used to assess the effect of IJE on protein expression of inducible NO synthase (iNOS) expression. Tumor necrosis factor-alpha (TNF- $\alpha$ ) cytokine production was evaluated by enzyme-linked immunosorbent assay (ELISA).

Results: Pretreatment of $100 \mathrm{mg} / \mathrm{ml}$ of IJE ( $p<0.001)$ was inhibited nitric oxide (NO) by $1 \mathrm{ug} / \mathrm{ml} \mathrm{LPS}$ treated BV-2 cells. iNOS and TNF- $\alpha$ expression were attenuated by IJE concentration-dependently ( $p<$ 0.001 at $100 \mathrm{mg} / \mathrm{ml}$ ). IJE scavenged 1, 1-diphenyl-2-picrylhydrazyl (DPPH) radicals in a dosedependently with half-maximal inhibitory concentration $\left(I C_{50}\right)$ value of $46.5 \mu \mathrm{g} / \mathrm{ml}$.

Conclusion: Data from this study indicate that IJE attenuates neuroinflammatory responses. The strong anti-oxidant effect of IJE modulates expression of inflammatory molecules at the transcription level, and TNF- $\alpha$ at post-transcription level.
\end{abstract}

Keywords: Isodon japonicas, Anti-oxidant, Neuroinflammation, BV-2 microglia, Nitric oxide

\begin{abstract}
This is an Open Access article that uses a funding model which does not charge readers or their institutions for access and distributed under the terms of the Creative Commons Attribution License (http://creativecommons.org/licenses/by/4.0) and the Budapest Open Access Initiative (http://www.budapestopenaccessinitiative.org/read), which permit unrestricted use, distribution, and reproduction in any medium, provided the original work is properly credited.
\end{abstract}

Tropical Journal of Pharmaceutical Research is indexed by Science Citation Index (SciSearch), Scopus, International Pharmaceutical Abstract, Chemical Abstracts, Embase, Index Copernicus, EBSCO, African Index Medicus, JournalSeek, Journal Citation Reports/Science Edition, Directory of Open Access Journals (DOAJ), African Journal Online, Bioline International, Open-J-Gate and Pharmacy Abstracts

\section{INTRODUCTION}

Inflammation is often considered a universally harmful event. The presence of cytotoxic cytokines, invading immune cells, and tissue destruction reinforces the idea that inflammation is synonymous with tissue pathology. Neuroinflammation has been considered a driver of pathology and cognitive dysfunction for many years; however, not all inflammation results in the same outcome. The brain is sensitive to a wide variety of inflammatory stimuli that can result in different outcomes depending on the type of exposure, environment, and underlying pathological processes. Neuroinflammation is a result of an innate immune response in the CNS. Being a "semi-immune privileged organ" the brain and spinal cord have many resident cell types capable of producing immune related factors that can trigger neuroinflammation (1). Astrocytes, microglia, and even neurons are all crucial players in maintaining tissue homeostasis, and in times of pathology, each of these cell types can contribute to an 
inflammatory response through cytokine secretion. Of these cells, microglia are thought to be the principle cell type that is pivotal in immune surveillance and maintaining homeostasis in the CNS. Such control is vital in the brain, which is the master regulator of many bodily functions. In particular, neurons have been shown to be extremely sensitive to neuroinflammation and can alter their connectivity depending on their environment (2). Microglia, the immune cells in the central nervous system (CNS), when activated produce several inflammatory mediators $[3,4]$, and may lead to progressive damage process in a number of neurodegenerative disorders including [4]. It is well known that microglia can be activated by lipopolysaccharide (LPS) and is recognized as a beneficial tool for studying neuroinflammatory mechanisms $[5,6]$. Thus, development of new anti-neuroinflammatory agents that reduce microglial activation and their proinflammatory responses is considered an important therapeutic strategy for neuroinflammatory disorders. Isodon japonicus, a perennial plant grown extensively in Korean peninsula has long been used as a traditional medicine $[7,8]$. However, till date the effect of Isodon japonicus (IJE) on neuroinflammation and LPS-activated microglial neurotoxicity has not been documented. The aim of this study was to investigate whether Isodon japonicus exhibits protective effects on LPSactivated neuroinflammatory processes in BV-2 microglial cells.

\section{EXPERIMENTAL}

\section{Plant materials and extraction}

Isodon japonicus was purchased from a local market in Chungnam, Korea in August 2013 and was authenticated by Dr JB Kim, a taxonomist at Konkuk University, Glocal Campus, Republic of Korea, and a voucher specimen (no. SGDKU2016) were stored in the herbarium of Dankook University, Korea for future reference. To obtain the Isodon japonicas, the material was washed in running tap water and chopped into smaller pieces. Isodon japonicas (200 g) was extracted with $1 \mathrm{~L}$ of water at $70^{\circ} \mathrm{C}$ for $2 \mathrm{~h}$. Water extracts were filtered and evaporated to dryness. The dried material was re-dissolved in $0.5 \mathrm{~L}$ of distilled water.

\section{Determination of free radical scavenging activity}

The anti-oxidant activity of the IJE was evaluated using the DPPH (Sigma-Aldrich, St. Louis, MO, USA). The radical scavenging capacity was determined by a reaction mixture constituted by aliquots of the IJE and a DPPH methanolic solution as described previously [14]. Furthermore, a sample solution of $30 \mu \mathrm{l}$, was added to $30 \mu \mathrm{L}$ of $\mathrm{DPPH}(30 \mu \mathrm{M})$ in methanol solvent. After mixing vigorously for $15 \mathrm{~s}$, the mixture was transferred into a $50 \mu \mathrm{L}$ capillary tube and the free radical activity of each sample on DPPH was measured by JES-FA ESR spectrometer (Jeol Ltd, Tokyo, Japan).

\section{Cell culture and viability assay}

Murine BV-2 microglia cells were cultured in $5 \%$ $\mathrm{CO}_{2}$ at $37{ }^{\circ} \mathrm{C}$ supplemented with $5 \% \mathrm{FBS}+$ DMEM (Hyclone, Logan, UT, USA). In all experiments, cells were pre-treated with IJE at concentrations from $10 \mu \mathrm{g} / \mathrm{ml}$ to $100 \mu \mathrm{g} / \mathrm{ml}$ ) for 1 $\mathrm{h}$. And then the addition of $1 \mu \mathrm{g} / \mathrm{ml}$ of LPS in serum-free DMEM.

For viability assay, BV-2 cells were plated onto 96 well plates and exposed to IJE. MTT reagent was added to each 96 well plate then incubated for $2 \mathrm{~h}$ in at $37{ }^{\circ} \mathrm{C}$. The supernatant was aspirated from the 96 wells and the blue formazan product obtained using DMSO. The samples in each of the 96 well were analyzed at $570 \mathrm{~nm}$ using Tecan microplate reader. Each experiment was conducted in triplicate. Percentage of the cell viability was convert the value to \%, (OD sample-OD medium)/(OD control -OD medium) x $100 \%$.

\section{Immunoblot analysis}

BV-2 Cells were washed in cold PBS (PH 7.4) three times and were lysed in a cell lysis buffer containing $25 \mathrm{mM}$ Tris- $\mathrm{HCl}, \mathrm{pH} 7.4,0.5 \%$ (v/v) NP-40, $0.20 \%$ sodium deoxycholate, $100 \mathrm{mM}$ Sodium Chloride , 0.5 mM EDTA, 20 mM NaF, 1 $\mathrm{mM} \mathrm{Na} \mathrm{Na}_{4}$ and protease inhibitor Complete Mini $^{\mathrm{TM}}$ cocktail (Roche, Mannheim, Germany) at $4^{\circ} \mathrm{C}$. The lysate was purified by centrifugation at $10,000 \mathrm{~g}$ for $10 \mathrm{~min}$ at $4^{\circ} \mathrm{C}$.

Cell lysates were normalized for protein content using Pierce BCA reagent (Rockford, IL, USA). Equal amounts of each protein were loaded onto $10 \%$ PAGE gels and were separated by standard SDS-PAGE procedure. And then, Proteins were transferred to a Nitro-cellulose membrane (Bio-Rad, Herculus, CA, USA) and blocked with $10 \%$ non-fat dry milk in PBS $(\mathrm{pH}$ 7.4). To detect iNOS protein expression, the blots were probed with the anti- iNOS followed by the rabbit-secondary antibodies coupled to horseradish peroxidase (Bio-Rad, Herculus, CA, USA). The detection of $\beta$-actin antibody was used for an internal control. The complexed proteins on the membrane were detected by 
chemiluminescence using the Pierce substrate on X-ray film. Anti-iNOS and anti- $\beta$-actin antibodies were purchased from Cell Signaling Technology Beverly, MA, USA).

\section{NO assay}

Production of nitric oxide was measured the levels of nitrite in the culture supernatant using colorimetric assay using Griess reagent [10]. Briefly, $2 \times 10^{5}$ cells $/ \mathrm{ml}$ of BV-2 cells were seeded in 6-well plates in $200 \mu \mathrm{l}$ complete culture medium and treated with the IJE at indicated concentrations for $30 \mathrm{~min}$ prior to stimulation with $1 \mu \mathrm{g} / \mathrm{ml}$ of LPS for $1 \mathrm{~h}$. Culture supernatant $(30 \mu \mathrm{l})$ was reacted with an equal volume of $0.1 \%$ naphthylethylenediamine and $1 \%$ sulfanilamide in $5 \% \mathrm{H}_{3} \mathrm{PO}_{4}$ (Griess reagent) in 96-well plates at room temperature. Each samples of nitrite oxide concentrations were measured by using a standard solutions of sodium nitrite. The absorbance was determined at $540 \mathrm{~nm}$ in Tecan microplate reader.

\section{TNF- $\alpha$ assay}

Murine BV-2 microglia cells were cultured on 96 well plates $\left(1 \times 10^{5}\right.$ cells/well) and treated with the IJE at indicated concentrations for $1 \mathrm{~h}$ and stimulated with LPS $(1 \mu \mathrm{g} / \mathrm{mL})$. At $4 \mathrm{~h}$ treatment with LPS, the cells were harvested and the supernatants (SNT) were measured for TNF- $\alpha$ levels using a TNF- $\alpha$ mouse ELISA kits from Invitrogen (Carlsbad, CA).

\section{Statistical analysis}

All data are presented as mean \pm SEM. Statistical significance $(p<0.05$ for all analyses) was assessed by ANOVA using Instat 3.05 (GraphPad, San Diego, CA), followed by Student-Newman-Keuls analysis.

\section{RESULTS}

\section{Effect of IJE on DPPH radical scavenging activity}

As shown in Figure $1 \mathrm{~A}$, IJE exhibited significant DPPH radical scavenging activity in a concentration-dependent manner showing a maximum effect at $200 \mu \mathrm{g} / \mathrm{ml}(p<0.001)$. The half maximal inhibitory concentration $\left(\mathrm{IC}_{50}\right)$ of $\mathrm{DPPH}$ free radicals was approximately 46.5 $\mu \mathrm{g} / \mathrm{mll}$.

\section{Effect of IJE on BV-2 cell viability}

As shown in Figure 2, treatment with IJE at 10 $200 \mu \mathrm{g} / \mathrm{ml}$ concentrations did not affect the cell viability nor ensured it exhibit any cytotoxicity on BV-2 microglia cells. The data indicated that the concentrations used in the study were safe to BV-2 microglial cells.

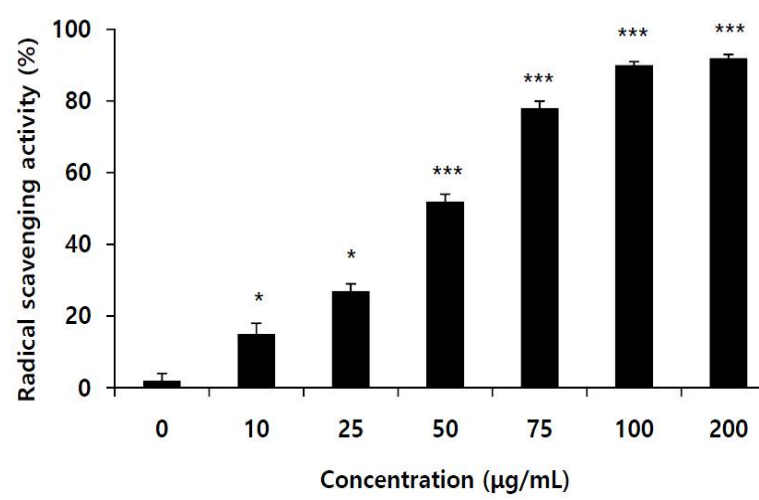

Figure 1: Effect of IJE on DPPH radical scavenging activity. The capacities to scavenge DPPH radicals by different concentrations of IJE. BV-2 cells were treated with or without IJE at the 10, 25, 50, 75, 100 and 200 $\mu \mathrm{g} / \mathrm{ml}$ concentrations (). All data are presented mean \pm S.E.M. $(n=4) ;{ }^{*} p<0.05$ and ${ }^{* * *} p<0.001$, compared with control group by Student t-test

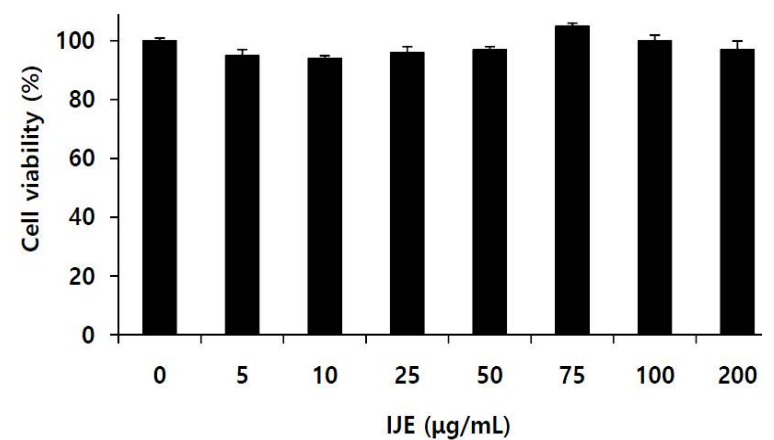

Figure 2: Effects of IJE on the viability of BV-2 microglial cells. Viability in IJE-treated BV-2 cells was evaluated using MTT assay. This results are depicted as percentage of control samples. All data are presented mean \pm SEM $(\mathrm{n}=4)$. IJE: Isodon japonicas extract

\section{IJE attenuates NO production in activated BV- 2 cells}

As shown in Figure 3, BV-2 cells treated with 1 $\mu \mathrm{g} / \mathrm{ml}$ of LPS alone significantly increased in NO (nitric oxide) levels $(p<0.001)$. Pre-treatment with IJE at indicated concentrations significantly and dose-dependently suppressed the excessive release of NO in BV-2 cells (Figure 3). Significant effect was observed at a concentration of 100 $\mu \mathrm{g} / \mathrm{ml}(p<0.001$

\section{IJE attenuates iNOS expression in activated BV-2 cells}

As shown in Figure 4, immunoblot analysis revealed that activation of $\mathrm{BV} 2$ microglia by lipopolysaccharide increased the protein 
expression levels of iNOS. However, the increased expression of iNOS in activated BV-2 cells was suppressed at a concentration of 20 $\mu \mathrm{g} / \mathrm{ml}$ and $40 \mu \mathrm{g} / \mathrm{ml}$ of IJE.

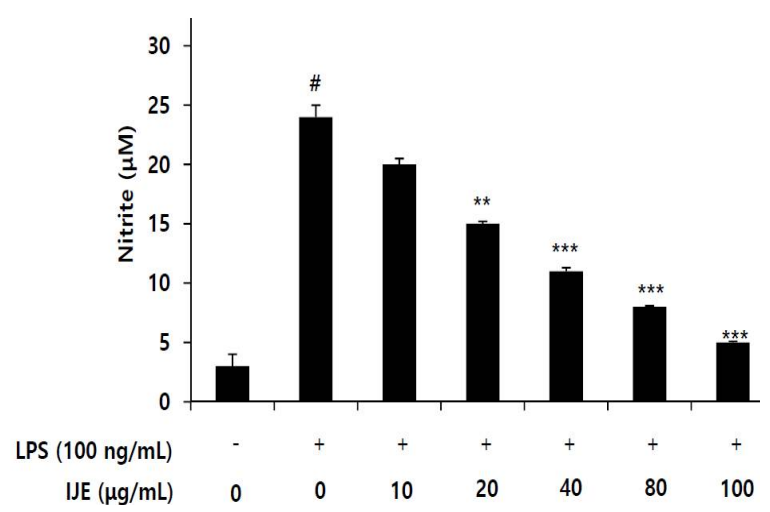

Figure 3: Effect of IJE on NO production in activated BV-2 cells. The nitrite in the culture supernatant was tested using Griess reagent. All data are presented mean \pm SEM $(\mathrm{n}=4) ;{ }^{\#} p<0.001$, when compared with control; ${ }^{* *} p<0.01$ and ${ }^{* * *} p<0.001$, when compared with LPS alone by Student t-test. (IJE: Isodon japonicas extract LPS: lipopolysaccharide).

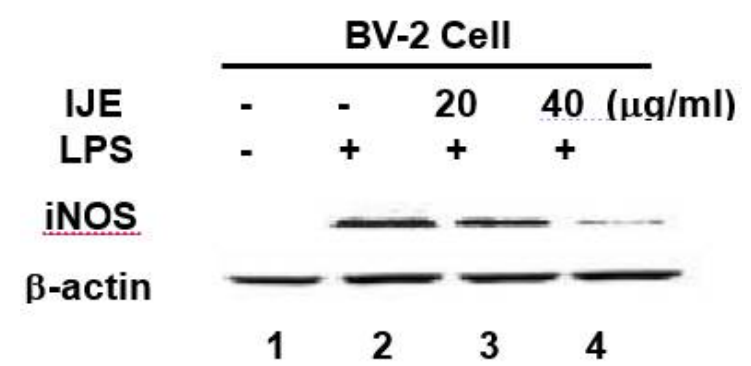

Figure 4: Effect of IJE on iNOS expressional levels in activating BV-2 microglial cells. The expression levels of iNOS protein in the LPS $(1 \mu \mathrm{g} / \mathrm{ml})$ - activated BV-2 cells by 40 and $80 \mu \mathrm{g} / \mathrm{ml}$ concentration of the IJE was measured by immunoblot analyses against anti-iNOS antibody. The internal control used was $\beta$-actin. (IJE: Isodon japonicas extract; LPS: Lipopolysaccharide; iNOS: Inducible nitric oxide).

\section{Effect of IJE on TNF- $\alpha$ in activated BV-2 cells}

Proinflammatory cytokine, TNF- $\alpha$ levels increased significantly after $1 \mu \mathrm{g} / \mathrm{ml}$ of LPS treatment when compared to those in LPSuntreated cells $(p<0.001)$ (Figure 5). However, IJE significantly attenuated TNF- $\alpha$ production in a dose dependent manner in activated BV-2 cells $(p<0.01$ at $50 \mu \mathrm{g} / \mathrm{ml}$ and $p<0.001$ at 100 and $200 \mu \mathrm{g} / \mathrm{ml}$, respectively).

\section{DISCUSSION}

This is the first report to demonstrate that IJE markedly inhibited LPS-induced inflammatory responses in the BV-2 microglial cell line. NO production and iNOS expression in BV-2 cells were significantly inhibited by IJE in a concentration-dependent manner. This protective effect of IJE was also evidenced by inhibiting TNF- $\alpha$ release. Moreover, the cell viability assay showed that treatment with $\mathrm{IJ}$ alone at various concentrations $(20-200 \mu \mathrm{g} / \mathrm{ml})$ did not have cytotoxic effects, whereas IJE significantly inhibited the inflammatory mediators stimulated by LPS.

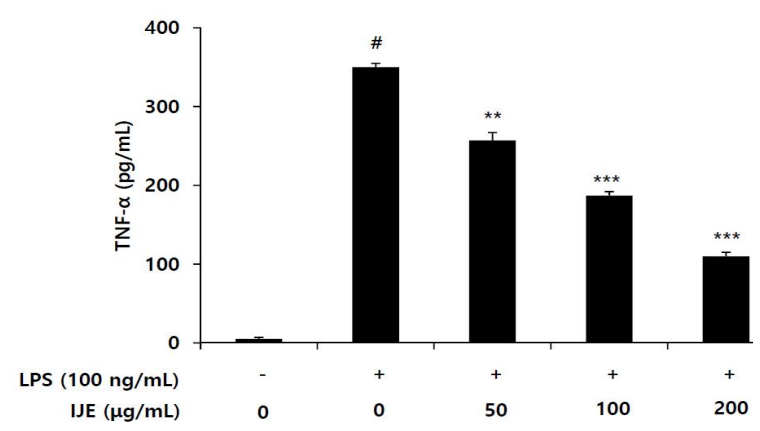

Figure 5: Effect of IJE on TNF- $\alpha$ production in activated BV-2 microglial cells. Suppression TNF- $\alpha$ expression by IJE was measured with ELISA test. BV2 cells were treated with IJE at $0,50,100$ and 200 $\mu \mathrm{g} / \mathrm{ml}$ with or without $1 \mu \mathrm{g} / \mathrm{ml}$ of LPS for $4 \mathrm{~h}$ incubation. All data are presented for four independent experiments as the mean \pm S.E.M. $(n=4)$; ${ }^{*} p<0.001$, when compared with control; ${ }^{* *} p<0.01$ and ${ }^{* * *} p<$ 0.001 , when compared with LPS alone by Student $\mathrm{t}-$ test. (IJE: Isodon japonicas extract; TNF-a: Tumor necrosis factor-alpha; LPS: lipopolysaccharide)

It is well accepted that activated microglia can produce various neurotoxic substances, including nitric oxide synthesized by iNOS mRNA expression. To assess the effect of IJE on LPSinduced NO production in BV2 cells, Griess reagent was used. NO is a crucial messenger and releasing NO can play a role in the neuronal pathway for cell to cell communication, leading to neuroinflammation. In this study, it was observed that IJE significantly suppressed iNOS protein production in both LPS-stimulated BV-2 microglial cells in a dose-dependent fashion. Activated microglial cells are known to release a proinflammatory cytokines including TNF- $\alpha$ which may not only intensify the inflammatory cascade, but also causes the inflammatory harm [11,12]. Therefore, IJE had an effect on the production of TNF- $\alpha$ in LPS-activated BV-2 microglial cells. The results indicate that IJE significantly suppressed the production of TNF- $\alpha$ in the LPSactivated BV-2 cells. Considering the data obtained it was suggested that IJE might have a potent anti-neuroinflammatory activity via the inhibition of TNF- $\alpha, N O$, as well as NOS protein in activated microglia cell.

The major focus of this thesis is the microglial 
response to neuroinflammation during disease. Therefore, the remaining parts of this introduction are devoted to microglial activation and immune function in the CNS. In addition, it propagates the release of inflammatory mediators responsible for the recruitment of additional neutrophils and macrophages in the CNS thereby hastening neuroinflammation [13]. Antioxidants and radical scavengers can reduce brain inflammation. DPPH free radical assay as one of the widely used methods for evaluating the free radical scavenging activities of several antioxidants [14]. Isodon japonicas is traditionally used in folk medicine to treat various ailments like tumors, gastrointestinal disorders, and inflammation.

Earlier reports revealed that IJE possess strong antioxidant compounds [8]. Previously, it had been demonstrated that IJE contains several phenolic compounds [9]. The antioxidant compounds such as kamebakaurin isolated from Isodon japonicas were well reported to have an anti-oxidant and anti-inflammatory activities [9]. In the present study, the IJE also exerted significant free radical scavenging effects, suggesting that IJE may contain anti-oxidant agents such as polyphenols.

\section{CONCLUSION}

The present study reports, for the first time, that IJE attenuates the neuro-inflammatory activity in activated murine BV-2 microglial cells. The antineuro-inflammatory effects of IJE might be attributed it its regulatory actions on the proinflammatory cytokine, TNF- $\alpha$, as well as its strong antioxidant effects. Therefore, IJE can potentially be developed for the treatment of microglia-mediated neuroinflammatory disease.

\section{DECLARATIONS}

\section{Competing interests}

The authors declare that no conflict of interest is associated with this work.

\section{Contribution of authors}

We declare that this work was done by the authors named in this article and all liabilities pertaining to claims relating to the content of this article will be borne by the authors.

\section{REFERENCES}

1. Nelson PT, Soma LA, Lavi E. Microglia in diseases of the central nervous system. Annal Med 2002; 34: 491-500.
2. Matsumoto $Y$, Ohmori $K$, Fujiwara M. Immune regulation by brain cells in the central nervous system: microglia but not astrocytes present myelin basic protein to encephalitogenic $T$ cells under in vivo mimicking conditions. Immunol 1992; 76: 209-216.

3. Gao HM, Jiang J, Wilson B, Zhang W, Hong JS, Liu B. Microglial activation-mediated delayed and progressive degeneration of rat nigral dopaminergic neurons: relevance to Parkinson's disease. J Neurochem 2002; 81: 1285-1297.

4. Kim SH, Smith CJ, Van Eldik LJ. Importance of MAPK pathways for microglial pro-inflammatory cytokine IL-1 $\beta$ production. Neurobiol Aging 2004a; 25: 431-439.

5. Park TK, Koppula S, Kim MS, Jung SH, Kang H. AntiNeuroinflammatory Effects of Houttuynia cordata Extract on LPS-Stimulated BV-2 Microglia. Trop J Pharm Res 2013; 12: 523-528.

6. Mizutani T, Shizuka F, Matsuzawa T, Amano Y, Arikawa Y. Anti-glycation activity of Japanese Chestnut (Castanea crenata) inner skin extract is beneficial for Type 2 Diabetes in a rat model. Anti-Aging Med 2014; 10: 112-119.

7. Hwang KA, Hwang YJ, Park DS, Kim J, Om AS. In vitro investigation of antioxidant and anti-apoptotic activities of Korean wild edible vegetable extracts and their correlation with apoptotic gene expression in HepG2 cells. Food Chem 2011; 125: 483-487.

8. Suzuki I, Kondoh M, Nagashima F, Fujii M, Asakawa Y, Watanabe YA. Comparison of apoptosis and necrosis induced by ent-kaurene-type diterpenoids in HL-60 cells. Planta Med 2004; 70: 401-406.

9. Nanjo F, Goto K, Seto R, Suzuki M. Scavenging effects of tea catechins and their derivatives on 1,1-diphenyl-2picrylhydrazyl radical. Free Radic Biol Med 1996; 21 : 895-902.

10. Kim BW, Koppula S, Kim IS, Lim HW. Antineuroinflammatory activity of Kamebakaurin from Isodon japonicus via inhibition of c-Jun NH-terminal kinase and p38 mitogen-activated protein kinase pathway in activated microglial cells. J Pharmacol Sci 2011; 116: 296-308.

11. Frankola KA, Greig NH, Luo W, Tweedie D. Targeting TNF-alpha to elucidate and ameliorate neuroinflammation in neurodegenerative diseases. CNS Neurol Disord Drug Targets 2011; 10: 391-403.

12. Perry RT, Collins JS, Wiener H, Acton R, Go RC. The role of TNF and its receptors in Alzheimer's disease. Neurobiol Aging 2001; 22: 873-883.

13. Beckman J, Beckman T, Chen J, Marshall P, Freeman B. Apparent hydroxyl radical production by peroxynitrite: implications for endothelial injury from nitric oxide and superoxide. Proc Natl Acad Sci U S A, 1990; 87: 16201624.

14. Rosenberg GA. Matrix metalloproteinases in neuroinflammation. Glia, 2002: 39: 279-291. 